\title{
Androgens Regulate the Development of Neuropathology in a Triple Transgenic Mouse Model of Alzheimer's Disease
}

\author{
Emily R. Rosario, ${ }^{1}$ Jenna C. Carroll, ${ }^{1}$ Salvatore Oddo, ${ }^{3}$ Frank M. LaFerla, ${ }^{3}$ and Christian J. Pike ${ }^{1,2}$ \\ ${ }^{1}$ Neuroscience Graduate Program and ${ }^{2}$ Davis School of Gerontology, University of Southern California, Los Angeles, California 90089, and ${ }^{3}$ Department of \\ Neurobiology and Behavior, University of California Irvine, Irvine, California 92697
}

\begin{abstract}
Normal age-related testosterone depletion in men is a recently identified risk factor for Alzheimer's disease (AD), but how androgen loss affects the development of $\mathrm{AD}$ is unclear. To investigate the relationship between androgen depletion and $\mathrm{AD}$, we compared how androgen status affects the progression of neuropathology in the triple transgenic mouse model of AD (3xTg-AD). Adult male 3xTg-AD mice were sham gonadectomized (GDX) or GDX to deplete endogenous androgens and then exposed for 4 months to either the androgen dihydrotestosterone (DHT) or to placebo. In comparison to gonadally intact 3xTg-AD mice, GDX mice exhibited robust increases in the accumulation of $\beta$-amyloid $(\mathrm{A} \beta)$, the protein implicated as the primary causal factor in $\mathrm{AD}$ pathogenesis, in both hippocampus and amygdala. In parallel to elevated levels of $\mathrm{A} \beta$, GDX mice exhibited significantly impaired spontaneous alternation behavior, indicating deficits in hippocampal function. Importantly, DHT treatment of GDX 3xTg-AD mice attenuated both A $\beta$ accumulation and behavioral deficits. These data demonstrate that androgen depletion accelerates the development of AD-like neuropathology, suggesting that a similar mechanism may underlie the increased risk for AD in men with low testosterone. In addition, our finding that DHT protects against acceleration of AD-like neuropathology predicts that androgen-based hormone therapy may be a useful strategy for the prevention and treatment of AD in aging men.
\end{abstract}

Key words: testosterone; Alzheimer's disease; dihydrotestosterone; $\beta$-amyloid; spontaneous alternation; neuropathology

\section{Introduction}

Advancing age is the most significant risk factor for the development of Alzheimer's disease (AD); however, the full range of age-related factors underlying this increased risk is not known. One recently identified age-related risk factor for $\mathrm{AD}$ in men is low testosterone (Pike et al., 2006). Testosterone, the primary male sex steroid hormone, is depleted gradually as a normal consequence of aging (Morley, 2001). Age-related loss of testosterone can manifest as a clinical syndrome of dysfunction and increased vulnerability to disease in androgen-responsive tissues (Morley, 2001). The brain is androgen-responsive, exhibits agerelated testosterone depletion (Rosario et al., 2004), and is vulnerable to senescent effects of androgen loss (Janowsky, 2006). Recent studies show that men with AD have significantly lower testosterone levels than aged men without AD (Hogervorst et al., 2001), suggesting that one neural effect of age-related testosterone loss in men is increased risk for AD. Importantly, testosterone depletion appears to occur well before clinical (Moffat et al., 2004) and neuropathological (Rosario et al., 2004) diagnosis of $\mathrm{AD}$, suggesting that low testosterone contributes to $\mathrm{AD}$ pathogenesis rather than results from it.

Received June 14, 2006; revised 0ct. 11, 2006; accepted Nov. 12, 2006.

This work was supported by grants from the Alzheimer's Association (IIRG-04-1274 to C.J.P.) and the National Institutes of Health (AG23739 to C.J.P., NS52143 to E.R.R., AG00093 to J.C.C.). We thank Dr. Larry Swanson for helpful discussions and Sara Kreimer for technical assistance.

Correspondence should be addressed to Dr. Christian J. Pike, Davis School of Gerontology, University of Southern California, 3715 McClintock Avenue, Los Angeles, CA 90089-0191. E-mail: cjpike@usc.edu.

DOI:10.1523/JNEUROSCI.2514-06.2006

Copyright $\odot 2006$ Society for Neuroscience $\quad$ 0270-6474/06/2613384-06\$15.00/0
How testosterone depletion increases the risk of $\mathrm{AD}$ remains to be established. Androgens exert several actions in brain potentially associated with protection against $\mathrm{AD}$, including neuroprotection (Pike, 2001) and attenuation of tau hyperphosphorylation (Papasozomenos, 1997). In addition, recent experimental findings indicate that androgens may reduce levels of soluble $\beta$-amyloid (A $\beta$ ) (Goodenough et al., 2000; Gouras et al., 2000; Ramsden et al., 2003), the protein widely implicated in the initiation of AD pathogenesis (Hardy and Selkoe, 2002). In aged men circulating levels of testosterone are correlated inversely with plasma levels of A $\beta$ (Gillett et al., 2003). Furthermore, prostate cancer therapy that depletes endogenous androgens and antagonizes androgen signaling results in elevated plasma levels of $\mathrm{A} \beta$ (Gandy et al., 2001; Almeida et al., 2004). Together, these studies establish a correlation between low testosterone and elevated $\mathrm{A} \beta$ levels, a finding consistent with the possibility that testosterone depletion in aging men may act as a risk factor for $\mathrm{AD}$ by increasing neural accumulation of $\mathrm{A} \beta$.

To investigate further the relationship between testosterone and $\mathrm{AD}$, we assessed how the development of $\mathrm{AD}$-like neuropathology in a triple transgenic mouse model of AD (3xTg-AD) (Oddo et al., 2003) is affected by androgen status. We report that androgen depletion in male $3 \mathrm{xTg}$-AD mice significantly accelerates both $\mathrm{A} \beta$ deposition and behavioral impairment, effects that are prevented by androgen treatment. These data represent the first experimental evidence directly linking androgen depletion to the development of AD-like neuropathology. 


\section{Materials and Methods}

Animals and hormone treatment. Colonies of male homozygous 3xTg-AD $\left(\mathrm{APP}_{\text {swe }}, \mathrm{PS}_{\mathrm{M} 146 \mathrm{~V}}, \mathrm{tau}_{\mathrm{P} 301 \mathrm{~L}}\right)$ (Oddo et al., 2003) and wild-type (B6129SF2/J; The Jackson Laboratory, Bar Harbor, ME) mice were bred and maintained in our vivarium, where they were housed individually under a $12 \mathrm{~h}$ light/dark schedule with ad libitum access to food and water. At age 3 months the mice ( $n=6-8$ /group) under pentobarbital (50 $\mathrm{mg} / \mathrm{kg}$ ) anesthesia either were gonadectomized (GDX) to deplete endogenous testosterone or were sham GDX and were implanted immediately with a subcutaneous 90 d continuous-release hormone pellet (Innovative Research of America, Sarasota, FL) containing either $10 \mathrm{mg}$ of dihydrotestosterone (DHT) or vehicle; animals received a second pellet $90 \mathrm{~d}$ later. At 4 months after initiation of hormone treatment, or at 3, 7, and 13 months of age for nontreatment groups, the animals were killed, and brains were collected, immersion-fixed in fresh $4 \%$ paraformaldehyde/ $0.1 \mathrm{M}$ PBS for $48 \mathrm{~h}$, and then stored at $4^{\circ} \mathrm{C}$ in $0.1 \mathrm{M} \mathrm{PBS} / 0.2 \%$ sodium azide. Efficacy of androgen manipulations was assessed at the time of death by weighing dissected and blotted seminal vesicles.

Immunohistochemistry. Fixed hemibrains were sectioned (40 $\mu \mathrm{m}) \mathrm{ex}-$ haustively in the horizontal plane with the use of a vibratome and then immunostained by using a standard protocol. Briefly, free-floating sections were immunolabeled with antibodies directed against $\mathrm{A} \beta$ (\#715800, 1:300 dilution; Zymed, San Francisco, CA) and A $\beta$ precursor protein (APP) C-terminal fragments (CTFs) (anti-APP-CT20, 1:16,000 dilution; Calbiochem, La Jolla, CA), using ABC Vector Elite and DAB kits (Vector Laboratories, Burlingame, CA). Before $\mathrm{A} \beta$ immunostaining the sections were pretreated for 5 min with $95 \%$ formic acid to enhance immunoreactivity.

Quantification of immunoreactivity. High-magnification fields from immunolabeled sections were digitized with a video capture system and then thresholded with NIH Image 1.61 software to separate positive and negative immunolabeling and to permit calculation of immunoreactive load, the percentage of area occupied by immunoreactive label. Mean load values were determined by sampling two to three non-overlapping representative fields from each brain region of interest (subiculum, hippocampus CA1, amygdala, and frontal cortex) in five separate sections per animal. Using this imaging technique, we also quantified load values for individual extracellular plaques (defined below) from 16-20 A $\beta$ immunostained sections per animal.

Quantification of extracellular plaques. Plaques were defined as extracellular $A \beta$-immunoreactive deposits that exhibited a spherical shape and morphology distinct from intraneuronal $\mathrm{A} \beta$ immunoreactivity. For quantification 16-20 A $\beta$-immunostained sections (beginning from dorsal hippocampus, $\sim 160-200 \mu \mathrm{m}$ apart) per brain were examined under light microscopy, and the total number of extracellular plaques was counted. Also, the area of each plaque was measured with NIH Image 1.61 software.

Spontaneous alternation behavior. Approximately 1 week before being killed, all mice were tested for spontaneous alternation behavior (SAB) in a Y-maze, a hippocampal-dependent task of working memory. Arm choices (both front and hind paws entering arm) were recorded while animals freely explored the maze for $8 \mathrm{~min}$. Mice that made 10 or fewer arm choices were excluded; only two animals across all groups were excluded. The SAB score was calculated as the proportion of alternations (an arm choice differing from each of two previous choices) to the total number of alternation opportunities (total arm entries, two), as described by King and Arendash (2002). For example, the arm choices A-A-B-C-B-B-A-C-C would be scored as two alternations (ABC and BAC) of seven opportunities $(9-2=7)$.

Statistical analyses. Raw data were analyzed by ANOVA, followed by between-group comparisons with Fisher's least significant difference test.

\section{Results}

\section{Male 3xTg-AD mice show age-dependent increases in} $\mathrm{A} \boldsymbol{\beta}$ accumulation

In agreement with previous observations in the $3 \mathrm{xTg}-\mathrm{AD}$ mouse (Oddo et al., 2003), we observed an age-dependent increase in $\mathrm{A} \beta$ that appeared to begin with neuronal accumulation and progress to extracellular deposition. Specifically, sham GDX male mice showed very low levels of neuronal $\mathrm{A} \beta$ immunoreactivity at age 3 months that increased substantially by age 7 months, with relative abundance in the following order: subiculum $>$ amygdala $>$ CA1 region of hippocampus (Fig. 1). A $\beta$ immunoreactivity was absent or present at comparatively low levels in frontal cortex at these time points (data not shown). Quantification of immunoreactive load confirmed a progressive age-dependent increase in $\mathrm{A} \beta$ accumulation across all three examined brain regions (Fig. $1 D, H, L)$. Extracellular plaque-like deposits appeared in some animals by age 7 months and in all animals by age 13 months $(F=$ 12.6; $p<0.01$ ), being most abundant in subiculum (Fig. 1C).

\section{Androgen depletion accelerates $\mathrm{A} \boldsymbol{\beta}$ accumulation}

So that the effect of androgen status could be investigated on the development of neuropathology, male $3 x T g-A D$ mice were depleted of endogenous androgens by GDX at age 3 months and treated immediately with DHT or placebo. To assess the efficacy of these experimental manipulations, we measured seminal vesicle weight, a bioassay of androgen status. Seminal vesicle weight was decreased significantly in the GDX group and significantly increased above sham GDX levels in the GDX plus DHT group, suggesting supraphysiological DHT replacement (sham GDX = $83.2 \pm 9.9 \mathrm{mg}, \mathrm{GDX}=15.8 \pm 4.7 \mathrm{mg}$, and GDX plus DHT $=$ $149 \pm 24 \mathrm{mg} ; F=21.6 ; p<0.001)$.

If androgen loss is a risk factor for $\mathrm{AD}$ in men, then experimental androgen depletion in male 3xTg-AD mice should accelerate the development of $\mathrm{AD}$-like neuropathology. Consistent with this prediction, we observed that GDX 3xTg-AD mice exhibited a robust increase in $\mathrm{A} \beta$ load in comparison to agematched sham GDX mice (Fig. 2). Importantly, DHT treatment of GDX animals completely prevented the increase in $\mathrm{A} \beta$ load in subiculum, CA1, and amygdala (Fig. 2).

We also determined how androgens affect extracellular $\mathrm{A} \beta$ deposition by comparing the number, load, and area of plaques across hormone conditions. Although there are few extracellular $\mathrm{A} \beta$ deposits at age 7 months, both the number $(F=4.3 ; p<0.05)$ and load $(F=4.6 ; p<0.05)$ of $\mathrm{A} \beta$ plaques were increased significantly in GDX 3xTg-AD animals in comparison to sham GDX animals, effects that were prevented by DHT treatment. In contrast, the mean plaque area did not vary across the sham GDX, GDX, and GDX plus DHT groups $(F=1.01 ; p=0.36)$, suggesting that androgen status does not affect plaque size significantly.

\section{Androgen depletion does not affect accumulation of APP CTFs}

Previous work demonstrated that $\mathrm{A} \beta$ immunoreactivity in $3 x T g-A D$ mice mainly represents oligomeric $A \beta$ species rather than CTFs of APP (Oddo et al., 2006). Both to verify this finding and to evaluate the potential effect of androgen status on CTF levels, we assessed CTF immunoreactivity across all groups. We found that, in contrast to the punctate appearance of $\mathrm{A} \beta \mathrm{immu}$ noreactivity in $3 \mathrm{xTg}-\mathrm{AD}$ mice (Fig. $3 \mathrm{C}$ ), CTF immunoreactivity is more even in appearance and mainly restricted to the cell perimeter (Fig. 3B). Although more abundant than levels in wildtype mice (Fig. 3A), CTF immunoreactivity in sham GDX $3 \times \mathrm{Tg}-\mathrm{AD}$ mice did not show a significant change with increasing age in subiculum, CA1 (Fig. 3D-G), or amygdala (data not shown). Notably, androgen status did not alter CTF immunoreactive load significantly (Fig. $3 H$ ). 

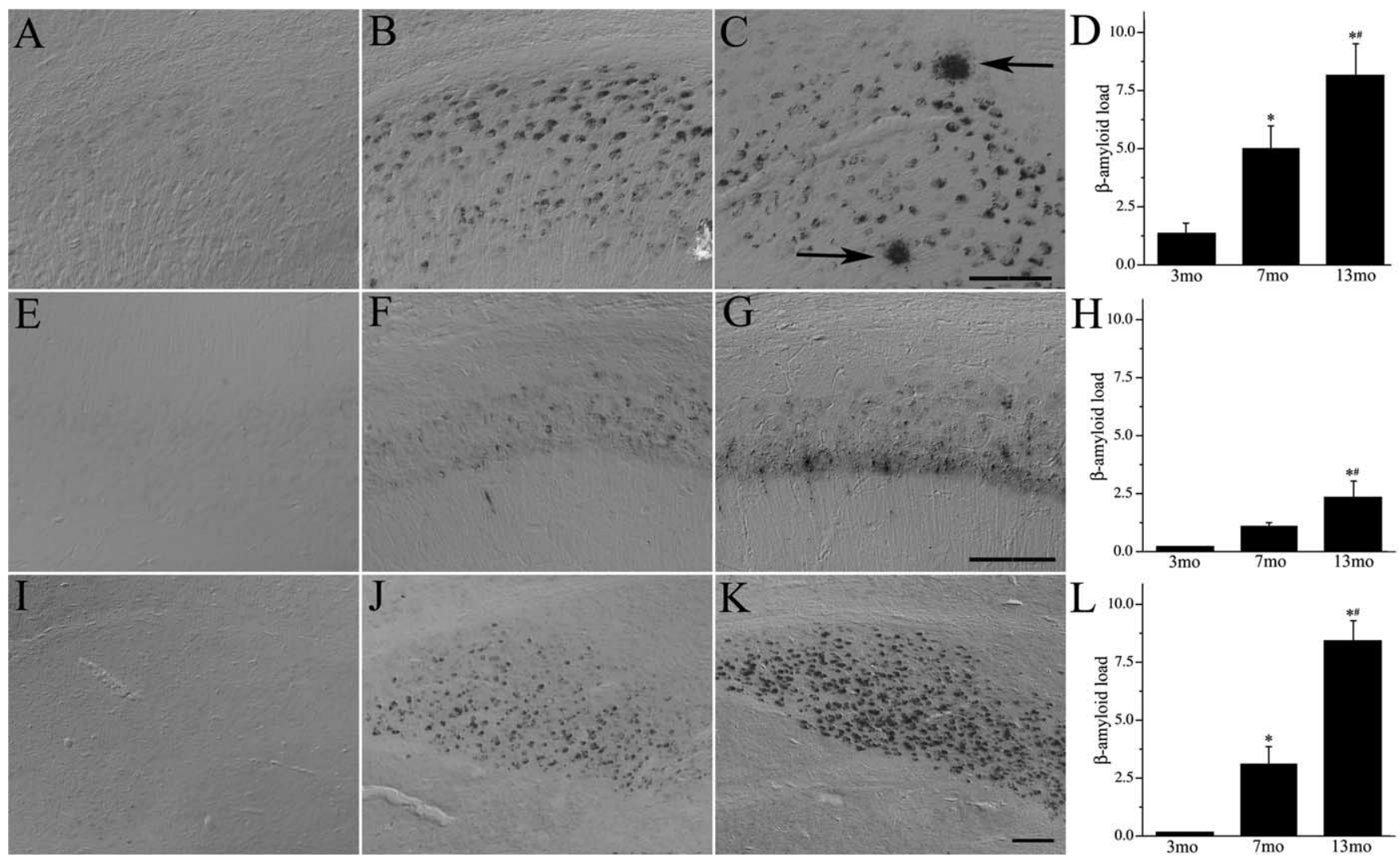

Figure 1. $A \beta$ accumulation increases with age in male $3 x \operatorname{Tg}-A D$ mice. Shown are representative photomicrographs of $A \beta$ immunoreactivity in sham GDX $3 \times T g-A D$ mice at ages $3(\boldsymbol{A}, \boldsymbol{E}, \boldsymbol{I}), 7(\boldsymbol{B}$, $\boldsymbol{F}, \boldsymbol{J})$, and $13(\boldsymbol{C}, \boldsymbol{G}, \boldsymbol{K})$ months in subiculum $(\boldsymbol{A}-\boldsymbol{C})$, hippocampus $C A 1(\boldsymbol{E}-\boldsymbol{G})$, and amygdala $(\boldsymbol{I}-\boldsymbol{K})$. Arrows show extracellular $A \beta$ deposits. Scale bars, $100 \mu \mathrm{m}$. $A \beta$ immunoreactivity in 3-, 7-, and 13-month-old 3xTg-AD mice was quantified by load values in subiculum (D), CA1 (H), and amygdala $(\boldsymbol{L})$. Data show the mean load values \pm SEM. ${ }^{*} p<0.05$ versus 3 month group; ${ }^{*} p<0.05$ versus 7 month group.

\section{Androgen depletion worsens behavioral performance in 3xTg-AD mice}

Next we evaluated the effects of aging and androgen status on behavioral performance in the $3 \mathrm{xTg}-\mathrm{AD}$ mice, using $\mathrm{SAB}$, a hippocampal-dependent behavior. We observed that, in comparison to wild-type mice, 3xTg-AD mice showed significantly impaired $\mathrm{SAB}$ that was apparent by age 7 months and mildly worse by age 13 months (Fig. $4 A$ ). Importantly, androgen status significantly affected SAB; androgen depletion in GDX mice worsened performance, and this effect was prevented by DHT treatment (Fig. $4 B$ ). To confirm that androgen regulation of SAB in $3 \mathrm{xTg}-\mathrm{AD}$ mice reflected androgen-induced effects on neuropathology rather than on behavior, we also assessed the effects of androgen depletion on SAB in wild-type male mice. SAB scores of GDX wild-type mice $(69.0 \pm 8.2)$ were not significantly different from sham GDX wild-type mice (73.1 $\pm 7.7 ; p=0.09)$. Finally, there were no significant group differences in the number of arm entries $(F=0.46 ; p=0.64)$, suggesting that activity levels were similar across the conditions.

\section{Discussion}

Recent studies in humans have implicated normal age-related testosterone depletion in men as a risk factor for the development of AD (Pike et al., 2006). In this study we report the first experimental investigation of this risk factor with the use of an animal model of AD. Specifically, we evaluated two hypotheses: (1) experimental androgen depletion should increase development of neuropathology, and (2) androgen treatment should prevent this acceleration of neuropathology. Consistent with the proposed regulatory role of androgens in $\mathrm{AD}$ pathogenesis, we observed that depletion of endogenous androgens in adult male $3 \times \mathrm{Tg}-\mathrm{AD}$ mice significantly accelerated the accumulation of $\mathrm{A} \beta$ and, in parallel, behavioral impairment. Importantly, acceleration of both pathologies was prevented by continuous treatment with the androgen DHT, although at apparently supraphysiological levels. Together, our results demonstrate that androgens regulate the development of AD-like neuropathology.

\section{Androgens are endogenous regulators of $\mathrm{A} \boldsymbol{\beta}$}

Although AD pathogenesis remains to be elucidated fully, the disease appears to be initiated by genetic and environmental factors that ultimately result in increased neural accumulation of $\mathrm{A} \beta$ (Hardy and Selkoe, 2002). Our data demonstrate that depletion of endogenous androgens robustly increases $\mathrm{A} \beta$ accumulation in brain, suggesting not only that normal androgen function is a regulator of neural $A \beta$ levels but also that the loss of this function can promote $\mathrm{AD}$ pathogenesis. Our findings are consistent with an emerging literature on sex steroid hormones and $\mathrm{A} \beta$. For example, estrogen alters metabolism (Jaffe et al., 1994) and trafficking (Greenfield et al., 2002) of APP, yielding reduced A $\beta$ levels in cultured cells (Xu et al., 1998) and wild-type rodents (Petanceska et al., 2000) by a mechanism that involves MAPK (mitogen-activated protein kinase) (Manthey et al., 2001) and/or PKC (protein kinase C) (Zhang et al., 2005) signaling and may interact with other risk factors for $A \beta$ accumulation including zinc (Lee et al., 2004). Additionally, A $\beta$ accumulation in females from some mouse models of $\mathrm{AD}$ is increased after estrogen depletion induced by aromatase knock-out (Yue et al., 2005) or 

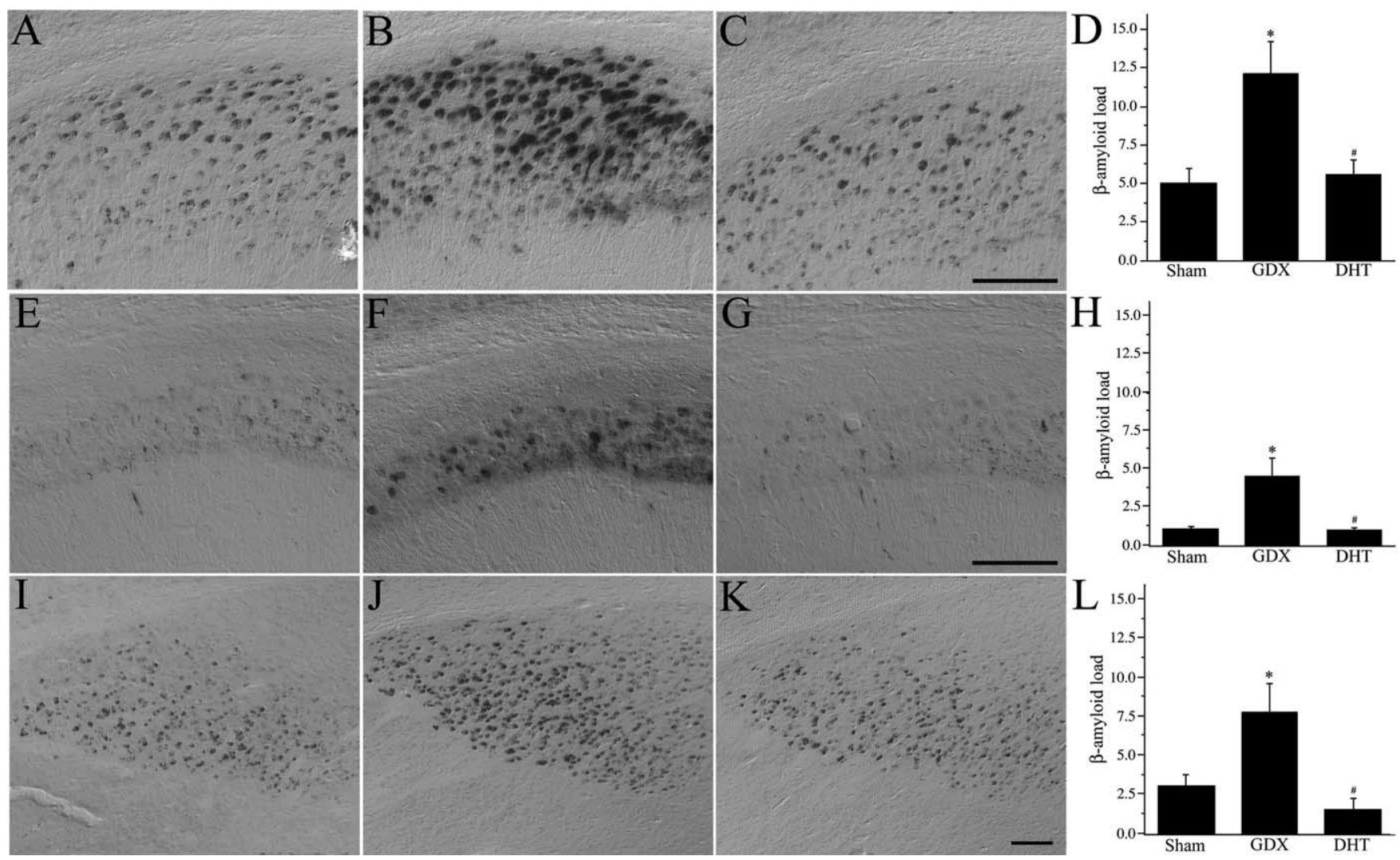

Figure 2. $A \beta$ accumulation is regulated by androgens. $A-C, E-G, I-K$, Representative photomicrographs show $A \beta$ immunoreactivity in male $3 \times T g-A D$ mice at age 7 months in the sham $G D X(A$, $\boldsymbol{E}, \boldsymbol{I}), \mathrm{GDX}(\boldsymbol{B}, \boldsymbol{F}, \boldsymbol{J})$, and GDX plus DHT $(\boldsymbol{C}, \boldsymbol{G}, \boldsymbol{K})$ conditions in subiculum $(\boldsymbol{A}-\boldsymbol{C}), \mathrm{CA1}(\boldsymbol{E}-\mathbf{G})$, and amygdala $(\boldsymbol{I}-\boldsymbol{K})$. Scale bars, $100 \mu \mathrm{m} . \boldsymbol{D}, \boldsymbol{H}, \boldsymbol{L}, \mathrm{A} \beta$ immunoreactivity in 7 month sham GDX (Sham), GDX, and GDX plus DHT 3xTg-AD mice was quantified by load values (means \pm SEM) in subiculum (D), $C A 1(\boldsymbol{H})$, and amygdala ( $(\boldsymbol{L}){ }^{*} p<0.05$ versus 7 month sham group; ${ }^{*} p<0.05$ versus 7 month $G D X$ group.
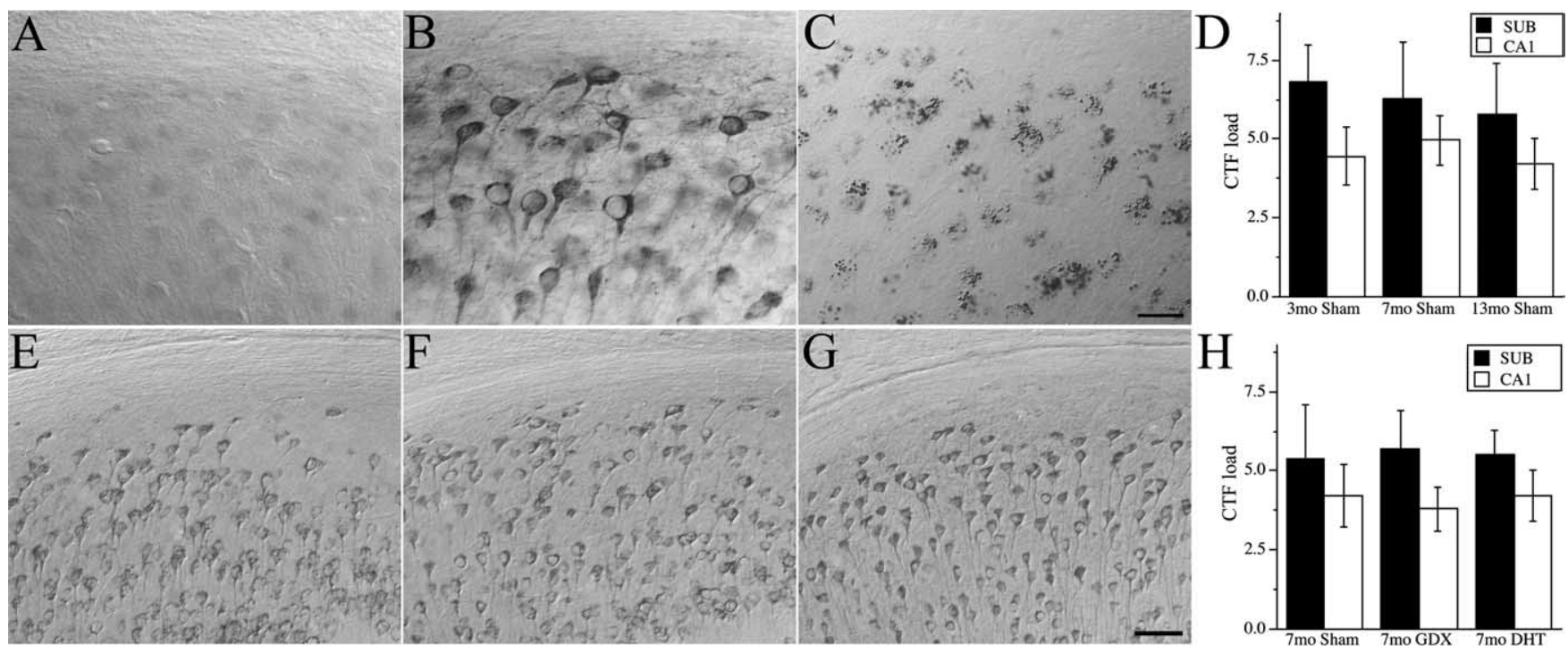

Figure 3. Accumulation of APP CTF does not change with age. $A, B$, Shown are representative photomicrographs of CTF immunoreactivity in subiculum in wild-type male $(\boldsymbol{A})$ and $3 \times \operatorname{TT}-\mathrm{AD}(\boldsymbol{B})$ mice at age 7 months. $C$, Representative photomicrograph of $A \beta$ immunoreactivity in subiculum in 7 month 3xTg-AD mouse. Scale bar, $25 \mu \mathrm{m}$. $\boldsymbol{E}-\boldsymbol{G}$ Also shown are representative photomicrographs of CTF immunoreactivity in subiculum of sham GDX 3xTg-AD mice at ages $3(\boldsymbol{E}), 7(\boldsymbol{F})$, and $13(\boldsymbol{G})$ months. Scale bar, $50 \mu \mathrm{m} . \boldsymbol{D}, \boldsymbol{H}, \mathrm{A} \beta$ immunoreactivity in subiculum (solid bars) and hippocampus CA1 (open bars) was quantified by load values (means \pm SEM) in sham GDX 3XTg-AD mice ages 3, 7, and 13 months (D) and 3xTg-AD mice age 7 months (H) in the sham GDX (Sham), GDX, and GDX plus DHT conditions.

ovariectomy (Levin-Allerhand et al., 2002; Zheng et al., 2002). Testosterone also can alter APP processing and reduce A $\beta$ levels in cultured cells (Goodenough et al., 2000; Gouras et al., 2000). In adult male rats GDX increases brain levels of soluble $\mathrm{A} \beta$, an effect prevented by the non-aromatizable DHT, but not by estrogen (Ramsden et al., 2003). It remains unclear to what extent androgens regulate $A \beta$ in female animals.

There is evidence that androgens also regulate $A \beta$ in men. For 
A
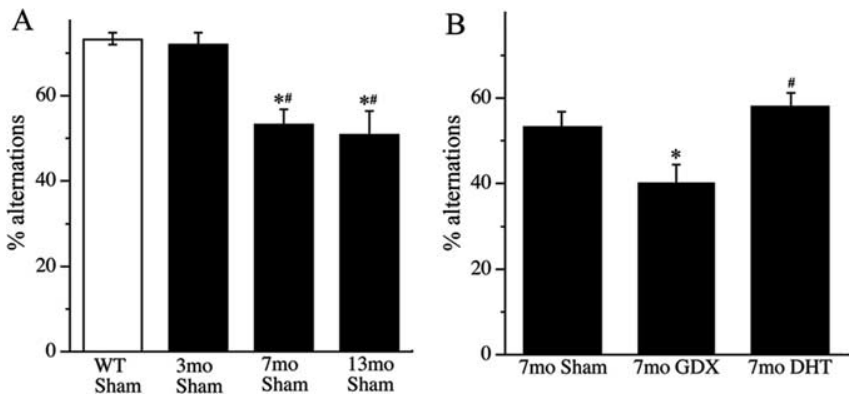

Figure 4. Advancing age and androgen depletion increase behavioral deficits in 3xTg-AD mice. Shown is $S A B$, expressed as a percentage of alternation $\pm S E M$, in wild-type (WT; open bars) and 3xTg-AD (solid bars) mice. $\boldsymbol{A}$, SAB decreased with increasing age in sham GDX (Sham) $3 x T g-A D$ mice. ${ }^{*} p<0.05$ versus 7 month WT Sham group; ${ }^{*} p<0.05$ versus 7 month Sham $3 x T g-A D$ group. $B, S A B$ was decreased by androgen depletion, an effect prevented by DHT treatment. ${ }^{*} p<0.05$ versus 7 month sham group; ${ }^{\#} p<0.05$ versus 7 month GDX group.

example, anti-androgen therapy for the treatment of prostate cancer is associated with increased levels of soluble $\mathrm{A} \beta$ in plasma (Gandy et al., 2001; Almeida et al., 2004). One concern is that anti-androgen therapy decreases both testosterone and estrogen levels, making it unclear which hormone or hormones are predominantly responsible for regulating $\mathrm{A} \beta$. However, in aged men not undergoing anti-androgen therapy, plasma $\mathrm{A} \beta$ levels inversely correlate with testosterone levels, but not with estrogen levels (Gillett et al., 2003).

The mechanism or mechanisms by which androgens regulate $\mathrm{A} \beta$ are not known. Testosterone can mediate cellular effects by three general pathways that are not mutually exclusive: activation of androgen receptor-dependent pathways, indirect activation of estrogen pathways via aromatization to estradiol, and modulation of gonadotropin actions via regulation of the hypothalamicpituitary-gonadal axis. Previous studies provide evidence that the observed androgen regulation of $\mathrm{A} \beta$ may involve individual or combined effects by all three pathways. Androgens are reported to regulate $\mathrm{A} \beta$ levels by estrogen-independent androgen pathways in male rodents (Ramsden et al., 2003) as well as by indirect estrogen-mediated APP metabolism in cultured cells (Goodenough et al., 2000). Also, recent work by Bowen and colleagues (2004) indicates $\mathrm{A} \beta$ regulation by the gonadotropinluteinizing hormone. Although future studies will be necessary to distinguish which of these pathways contribute to the present androgen effects, our finding that DHT treatment prevented the acceleration of $\mathrm{AD}$-like neuropathology in GDX $3 \times \mathrm{Tg}$ - $\mathrm{AD}$ mice is consistent with an estrogen-independent mechanism, because DHT is not aromatized to estrogen. However, a recent report suggests that the DHT metabolite $5 \alpha$-androstan- $3 \beta, 17 \beta$-diol can have agonist actions on estrogen receptor $\beta$ (Lund et al., 2006). Regardless of the underlying mechanism or mechanisms, our results clearly demonstrate that a loss of androgens leads to an increase in $\mathrm{A} \beta$ accumulation.

\section{Androgens regulate progression of cognitive impairment}

Because androgens regulate $A \beta$ accumulation and $A \beta$ impairs cognitive function, androgens are predicted to affect the development of cognitive dysfunction. Previous work has established that, without causing neuron death, $\mathrm{A} \beta$ can disrupt the synaptic plasticity necessary for normal cognitive functions, including learning and memory (Walsh and Selkoe, 2004). In 3xTg-AD mice an accumulation of $\mathrm{A} \beta$ does not appear to cause significant neuron loss but does impair long-term potentiation (Oddo et al., 2003) and various measures of behavioral performance (Billings et al., 2005). In this study $A \beta$ was observed to accumulate at significant levels in limbic regions by age 7 months, the same time point at which hippocampal-dependent SAB became impaired. Prevention of $A \beta$ accumulation in $3 x T g-A D$ mice attenuates behavioral impairments (Billings et al., 2005), strengthening the link between $A \beta$ accumulation and behavioral performance in this model. Thus our observation that DHT treatment blocked the GDX-induced decrease in SAB suggests that the androgen effect was mediated by regulation of $\mathrm{A} \beta$ accumulation. Arguing against a significant direct androgen effect on $S A B$ was our observation that androgen status did not affect $S A B$ in wild-type mice.

In both rodent and human studies androgens can exert beneficial cognitive effects (Cherrier et al., 2005; Janowsky, 2006). For example, in transgenic mice overexpressing the $\mathrm{AD}$ genetic risk factor apolipoprotein E4, females exhibit cognitive deficits that are prevented by testosterone, whereas males exhibit deficits only if treated with an androgen receptor antagonist (Raber et al., 2002). Interestingly, chronic androgen depletion in male apolipoprotein E4 mice impaired performance on some behavioral tasks but improved performance on others (Pfankuch et al., 2005), suggesting a complex relationship among androgens, apolipoprotein E, and behavior. In men with clinically significant age-related testosterone depletion, androgen supplementation can improve mood and some cognitive abilities (Alexander et al., 1998). In contrast, reduction of androgen and estrogen levels and/or inhibition of androgen signaling by anti-androgen prostate cancer therapies can impair some aspects of cognition (Green et al., 2002; Salminen et al., 2005). Interestingly, discontinuation of anti-androgen treatment resulted in restored plasma testosterone levels that correlated with improved cognitive performance on some tasks and reduced plasma levels of $\mathrm{A} \beta$ (Almeida et al., 2004). Thus our findings extend a growing literature indicating that androgens can benefit cognitive abilities significantly by mechanisms that may include a reduction of $\mathrm{A} \beta$ levels.

\section{Androgens and the prevention of Alzheimer's disease}

Androgen loss, which occurs as a consequence of normal aging in men, can promote disease and dysfunction in androgenresponsive tissues including the brain (Morley, 2001). Recent studies have linked age-related testosterone depletion with increased risk of AD (Hogervorst et al., 2001; Moffat et al., 2004; Rosario et al., 2004). Our findings demonstrate that, in an animal model of AD, experimental depletion of endogenous androgens accelerates the development of both $\mathrm{AD}$-like neuropathology and behavioral impairment. Importantly, our data also show that androgen treatment prevents the increase in pathology progression. These findings not only demonstrate a significant role of androgen depletion in $\mathrm{AD}$ pathogenesis but also predict that androgen-based therapeutics may function effectively in the prevention of AD.

\section{References}

Alexander GM, Swerdloff RS, Wang C, Davidson T, McDonald V, Steiner B, Hines M (1998) Androgen-behavior correlations in hypogonadal men and eugonadal men. II. Cognitive abilities. Horm Behav 33:85-94.

Almeida OP, Waterreus A, Spry N, Flicker L, Martins RN (2004) One year follow-up study of the association between chemical castration, sex hormones, beta-amyloid, memory, and depression in men. Psychoneuroendocrinology 29:1071-1081.

Billings LM, Oddo S, Green KN, McGaugh JL, LaFerla FM (2005) Intraneuronal $\mathrm{A} \beta$ causes the onset of early Alzheimer's disease-related cognitive deficits in transgenic mice. Neuron 45:675-688.

Bowen RL, Verdile G, Liu T, Parlow AF, Perry G, Smith MA, Martins RN, 
Atwood CS (2004) Luteinizing hormone, a reproductive regulator that modulates the processing of amyloid- $\beta$ precursor protein and amyloid- $\beta$ deposition. J Biol Chem 279:20539-20545.

Cherrier MM, Matsumoto AM, Amory JK, Asthana S, Bremner W, Peskind ER, Raskind MA, Craft S (2005) Testosterone improves spatial memory in men with Alzheimer disease and mild cognitive impairment. Neurology 64:2063-2068.

Gandy S, Almeida OP, Fonte J, Lim D, Waterreus A, Spry N, Flicker L, Martins RN (2001) Chemical andropause and amyloid- $\beta$ peptide. JAMA 285:2195-2196.

Gillett MJ, Martins RN, Clarnette RM, Chubb SA, Bruce DG, Yeap BB (2003) Relationship between testosterone, sex hormone binding globulin, and plasma amyloid beta peptide 40 in older men with subjective memory loss or dementia. J Alzheimers Dis 5:267-269.

Goodenough S, Engert S, Behl C (2000) Testosterone stimulates rapid secretory amyloid precursor protein release from rat hypothalamic cells via the activation of the mitogen-activated protein kinase pathway. Neurosci Lett 296:49-52.

Gouras GK, Xu H, Gross RS, Greenfield JP, Hai B, Wang R, Greengard P (2000) Testosterone reduces neuronal secretion of Alzheimer's $\beta$-amyloid peptides. Proc Natl Acad Sci USA 97:1202-1205.

Green HJ, Pakenham KI, Headley BC, Yaxley J, Nicol DL, Mactaggart PN, Swanson C, Watson RB, Gardiner RA (2002) Altered cognitive function in men treated for prostate cancer with luteinizing hormone-releasing analogues and cyproterone acetate: a randomized controlled trial. BJU Int 90:427-432.

Greenfield JP, Leung LW, Cai D, Kaasik K, Gross RS, Rodriguez-Boulan E, Greengard P, Xu H (2002) Estrogen lowers Alzheimer $\beta$-amyloid generation by stimulating trans-Golgi network vesicle biogenesis. J Biol Chem 277:12128-12136.

Hardy J, Selkoe DJ (2002) The amyloid hypothesis of Alzheimer's disease: progress and problems on the road to therapeutics. Science 297:353-356.

Hogervorst E, Williams J, Budge M, Barnetson L, Combrinck M, Smith AD (2001) Serum total testosterone is lower in men with Alzheimer's disease. Neuro Endocrinol Lett 22:163-168.

Jaffe AB, Toran-Allerand CD, Greengard P, Gandy SE (1994) Estrogen regulates metabolism of Alzheimer amyloid $\beta$ precursor protein. J Biol Chem 269:13065-13068.

Janowsky JS (2006) The role of androgens in cognition and brain aging in men. Neuroscience 138:1015-1020.

King D, Arendash GW (2002) Behavioral characterization of the Tg2576 transgenic model of Alzheimer's disease through 19 months. Physiol Behav 75:627-642.

Lee JY, Kim JH, Hong SH, Cherny RA, Bush AI, Palmiter RD, Koh JY (2004) Estrogen decreases zinc transporter 3 expression and synaptic vesicle zinc levels in mouse brain. J Biol Chem 279:8602-8607.

Levin-Allerhand JA, Lominska CE, Wang J, Smith JD (2002) $17 \alpha$-estradiol and $17 \beta$-estradiol treatments are effective in lowering cerebral amyloid- $\beta$ levels in A $\beta$ PPSWE transgenic mice. J Alzheimers Dis 4:449-457.

Lund TD, Hinds LR, Handa RJ (2006) The androgen $5 \alpha$-dihydrotestosterone and its metabolite $5 \alpha$-androstan- $3 \beta, 17 \beta$-diol inhibit the hypothalamo-pituitary-adrenal response to stress by acting through estrogen receptor $\beta$-expressing neurons in the hypothalamus. J Neurosci 26:1448-1456.

Manthey D, Heck S, Engert S, Behl C (2001) Estrogen induces a rapid secre- tion of amyloid beta precursor protein via the mitogen-activated protein kinase pathway. Eur J Biochem 268:4285-4291.

Moffat SD, Zonderman AB, Metter EJ, Kawas C, Blackman MR, Harman SM, Resnick SM (2004) Free testosterone and risk for Alzheimer disease in older men. Neurology 62:188-193.

Morley JE (2001) Androgens and aging. Maturitas 38:61-71.

Oddo S, Caccamo A, Shepherd JD, Murphy MP, Golde TE, Kayed R, Metherate R, Mattson MP, Akbari Y, LaFerla FM (2003) Triple-transgenic model of Alzheimer's disease with plaques and tangles: intracellular $\mathrm{A} \beta$ and synaptic dysfunction. Neuron 39:409-421.

Oddo S, Caccamo A, Smith IF, Green KN, LaFerla FM (2006) A dynamic relationship between intracellular and extracellular pools of $\mathrm{A} \beta$. Am J Pathol 168:184-194.

Papasozomenos SC (1997) The heat shock-induced hyperphosphorylation of tau is estrogen-independent and prevented by androgens: implications for Alzheimer disease. Proc Natl Acad Sci USA 94:6612-6617.

Petanceska SS, Nagy V, Frail D, Gandy S (2000) Ovariectomy and $17 \beta$ estradiol modulate the levels of Alzheimer's amyloid $\beta$ peptides in brain. Exp Gerontol 35:1317-1325.

Pfankuch T, Rizk A, Olsen R, Poage C, Raber J (2005) Role of circulating androgen levels in effects of apoE4 on cognitive function. Brain Res 1053:88-96.

Pike CJ (2001) Testosterone attenuates beta-amyloid toxicity in cultured hippocampal neurons. Brain Res 919:160-165.

Pike CJ, Rosario ER, Nguyen TV (2006) Androgens, aging, and Alzheimer's disease. Endocrine 29:233-241.

Raber J, Bongers G, LeFevour A, Buttini M, Mucke L (2002) Androgens protect against apolipoprotein E4-induced cognitive deficits. J Neurosci 22:5204-5209.

Ramsden M, Nyborg AC, Murphy MP, Chang L, Stanczyk FZ, Golde TE, Pike CJ (2003) Androgens modulate beta-amyloid levels in male rat brain. J Neurochem 87:1052-1055.

Rosario ER, Chang L, Stanczyk FZ, Pike CJ (2004) Age-related testosterone depletion and the risk for Alzheimer's disease. JAMA 292:1431-1432.

Salminen EK, Portin RI, Koskinen AI, Helenius HY, Nurmi MJ (2005) Estradiol and cognition during androgen deprivation in men with prostate carcinoma. Cancer 103:1381-1387.

Walsh DM, Selkoe DJ (2004) Deciphering the molecular basis of memory failure in Alzheimer's disease. Neuron 44:181-193.

Xu H, Gouras GK, Greenfield JP, Vincent B, Naslund J, Mazzarelli L, Fried G, Jovanovic JN, Seeger M, Relkin NR, Liao F, Checler F, Buxbaum JD, Chait BT, Thinakaran G, Sisodia SS, Wang R, Greengard P, Gandy S (1998) Estrogen reduces neuronal generation of Alzheimer beta-amyloid peptides. Nat Med 4:447-451.

Yue X, Lu M, Lancaster T, Cao P, Honda S, Staufenbiel M, Harada N, Zhong $Z$, Shen Y, Li R (2005) Brain estrogen deficiency accelerates A $\beta$ plaque formation in an Alzheimer's disease animal model. Proc Natl Acad Sci USA 102:19198-19203.

Zhang S, Huang Y, Zhu YC, Yao T (2005) Estrogen stimulates release of secreted amyloid precursor protein from primary rat cortical neurons via protein kinase C pathway. Acta Pharmacol Sin 26:171-176.

Zheng H, Xu H, Uljon SN, Gross R, Hardy K, Gaynor J, Lafrancois J, Simpkins J, Refolo LM, Petanceska S, Wang R, Duff K (2002) Modulation of A $\beta$ peptides by estrogen in mouse models. J Neurochem 80:191-196. 